Cuadernos de Filología Clásica. Estudios Latinos

ISSN: 1131-9062

https://dx.doi.org/10.5209/cfcl.77311

\title{
El mito de Adonis y Venus en la comedia mitológica de Lope de Vega y Calderón de la Barca
}

\author{
$\mathrm{M}^{\mathrm{a}}$ Cruz García Fuentes ${ }^{1}$
}

Recibido: 21 de octubre de 2020 / Aceptado: 8 de junio de 2021

Resumen. Este artículo centra su atención en el mito de Venus y Adonis, tratado por Lope de Vega en su comedia mitológica Adonis y Venus y en la de Calderón La púrpura de la rosa. Analizamos el texto de Ovidio (Met. X 525-739), fuente de inspiración para estos dramaturgos, indicamos los ecos ovidianos y las innovaciones que estos poetas, gracias a su creatividad, incluyeron en sus obras para enriquecer y complicar la acción. Lope reescribe la totalidad del mito, presenta una obra desmitificada y con personalidad propia. Calderón sólo desarrolla el mito principal y ofrece una interpretación filosófica y ejemplarizante.

Palabras clave: Comedia mitológica; Lope, Venus y Adonis; Calderón, La púrpura de la rosa.

[en] The myth of Adonis and Venus in the mythological comedy of Lope de Vega and Calderón de la Barca

Abstract. This article focuses on the myth of Venus and Adonis, treated by Lope de Vega in his mythological comedy Adonis and Venus and Calderón's The Purple of the Rose. We analyze Ovid's text (Met. X 525-739), source of inspiration for these playwrights, we indicate the Ovid echoes and the innovations that these poets, thanks to their creativity, included in their works in order to enrich and complicate the action. Lope rewrites the entire myth, presents a demystified work with its own personality. Calderón only develops the main myth and offers an exemplary and philosophical interpretation.

Keywords: The mythological comedy; Lope, Venus y Adonis; Calderón, La púrpura de la rosa.

Sumario. 1. Introducción. 2. La comedia mitológica. 3. Adonis y Venus de Lope de Vega. 4. La púrpura de la rosa de Calderón de la Barca. 5. Conclusiones. 6. Referencias bibliográficas.

Cómo citar: García Fuentes, $\mathrm{M}^{\mathrm{a}} \mathrm{C}$. «El mito de Adonis y Venus en la comedia mitológica de Lope de Vega y Calderón de la Barca», Cuad. Filol. Clás. Estud. Lat. 41.1 (2021), 123-141.

\section{Introducción}

El período más brillante y fructífero de la dramaturgia española es el Siglo de Oro, gracias al talento y a la creatividad de las dos figuras señeras de esta época: Lope de Vega y Calderón. Ambos dramaturgos utilizaron, en parte de su producción teatral, la mitología no sólo como erudición, sino como tema de sus poesías, fábulas y comedias mitológicas, inspirándose en los mitos clásicos, especialmente los transmitidos por Ovidio en sus Metamorfosis.

1 Universidad Complutense de Madrid. Correo electrónico: margarfu@ucm.es. 
Los mitos clásicos perviven en el teatro del Siglo de Oro porque los dramaturgos han sabido actualizar y reinterpretar ese contenido, encarnando en los personajes mitológicos los problemas, inquietudes, valores, sentimientos y gustos propios del hombre del siglo XVII y esto ha sido posible gracias a dos razones fundamentales: primero, a la adaptabilidad de éstos a cualquier cultura, sociedad y momento histórico y segundo, al hecho de que las actuaciones y comportamientos de los protagonistas del mito son inherentes a la naturaleza humana y a su desarrollo vital, lo que hace que sean atemporales e incluso, en muchas ocasiones, ejemplarizantes.

\section{La comedia mitológica}

Este tipo de composición es uno de los géneros de la dramática de este siglo que trata el mito con mayor libertad que ningún otro género literario, por las exigencias de la representación que obligan a presentar en escena personajes secundarios para enriquecer y complicar la acción. Lope fue el iniciador de estas composiciones en España, al encargarle Felipe IV, en 1629, para celebrar la llegada de la reina de Hungría (la infanta María), la puesta en escena, en el Salón de Comedias de Palacio, de una comedia pastoril, La selva sin amor, distinta de las otras al ser totalmente cantada, siguiendo la influencia de las obras italianas, y con la escenografía de Cosimo Lotti. A Calderón, por el contrario, se le considera el verdadero maestro y consolidador de la comedia mitológica, al tomar como modelo la ópera italiana (Arróniz 1969) a la que libró de afectación, llegando a conseguir la mayor plenitud de estas composiciones al haber sabido ofrecer a la Corte un tipo de comedia que aunaba en ellas espectáculo, poesía, pintura ${ }^{2}$ y música. Sin embargo, este tipo de drama calderoniano fue menospreciado e ignorado durante gran parte del siglo XIX, e incluso se le llegó a considerar un apéndice secundario de su extensa producción, pero hace algunos años que gozan de mayor consideración, gracias a la labor realizada por Menéndez y Pelayo, Chapman, Valbuena Prat y otros muchos filólogos.

La temática que predomina en estas comedias es preferentemente la amorosa con sus rivalidades, celos, desengaños y venganzas. Con todo, tiene gran importancia el tema del honor, la fama, la misoginia, el elogio de la vida en la naturaleza y el destino. Haverbeck (1975) afirma que los rasgos de las comedias mitológicas coinciden con los rasgos típicos de la comedia tradicional española, especialmente con los de la comedia de enredo de tipo palaciego.

Es interesante saber que estas comedias se imprimían después de ser representadas y que su representación normalmente se realizaba en la corte, en el palacio del Buen Retiro o en los reales sitios, donde la tramoya y la espectacularidad era, a veces, más importante que la obra poética3. Éstas reciben el nombre de "comedias de tramoya" y se convirtieron, en la producción calderoniana, en aparatosos dramas

2 Egido $(2000,195)$ considera que el motivo de que apareciese en La púrpura de la rosa un espejo en la gruta, se debía a la estrecha relación que existía entre la obra de Calderón y la pintura de Velázquez que había pintado un lienzo de Venus y Adonis para el Salón de los Espejos del Alcázar.

3 Cancelliere $(2001,121)$ declara: "La presencia de la música en algunas partes de la comedia testimonia el influjo del teatro musical italiano en el teatro de Calderón. La comedia palaciega se caracteriza, de hecho, por unas constantes: el tema tratado ha de ser relevante y debe permitir el juego natural de las tramoyas, del lujo entre personajes que, a la fuerza, serán prodigiosos y, a la fuerza, tendrán que salir con música en las ocasiones portentosas". Más información sobre el tema la encontramos en Becker, (1986, 353-364). 
que necesitaban un gran apoyo de lo espectacular ${ }^{4}$ y de lo visual, con gran acompañamiento de música y danza, en las que el poeta ocupaba una posición inferior al maquinista y al pintor escenográfico y ofrecían al espectador culto un tema conocido, con una intriga bastante simple. Arellano $(1995,93)$ considera que la fusión de lo visual, lo sonoro musical y lo poético es la marca de este teatro de corte del período barroco. Estas obras además de funcionar como espectáculo festivo, para ocasiones especiales de nacimientos principescos, bodas, onomástica de reyes o celebración política, lo hacen como simbolismo filosófico y moral, incluso probablemente con la intención de mostrar una alegoría política (Mckendrick 1994, 176).

2.1. Lope de Vega fue el primero que diseño y popularizó la forma dramática que recibe el nombre de "comedia del Siglo de Oro" y sentó las bases para la comedia mitológica al establecer, en El arte nuevo de hacer comedias, una serie de innovaciones que siguieron respetando los dramaturgos que componían estas obras:

1. Personajes nobles aparecían mezclados con otros de condición social más humilde, que ayudaban a duplicar la acción y tenían una gran relevancia en la construcción del discurso mitológico lopesco.

2. El mito se actualizaba, introduciendo pastores y labradores que cantaban, bailaban y jugaban, para ofrecer un relato más real y cercano a la sociedad de su tiempo, aunque con ciertos anacronismos.

3. Se mezclaba lo trágico y lo cómico en el mismo relato, creando la tragicomedia.

4. El drama se dividía en tres actos y se utilizaba un lenguaje apropiado a la situación y al personaje.

5. Se crea la figura del gracioso ${ }^{6}$ que suele ser el sirviente del noble o del héroe y sobre el que recae la comicidad. Es un personaje nuevo, aunque algunos estudiosos consideran que su modelo más directo se encuentra en los esclavos de la comedia de Plauto y de Terencio. Ocupa una posición privilegiada $\mathrm{y}$, a pesar de su bajo nivel cultural, representa la vertiente materialista y posee una sabiduría innata que muestra en su actitud cobarde, fiel, burlesca, irónica y crítica de la realidad, propiciando la comicidad por los comentarios, juegos de palabras, retruécanos y homonimias. Es elemento clave para que la acción esté más cerca de la realidad cotidiana, prolongándola con acierto, gracia, y donaire, aunque no siempre se limita a ser una figura cómica. Es un componente esencial y propio de este tipo de composición que fue mantenido por Calderón de la Barca y sus seguidores en sus comedias. En efecto, la estética lopesca mantendrá su vigencia a lo largo de casi todo el siglo XVII definiendo los rasgos del teatro español de dicha centuria (Haverbeck 2006, 508).

4 Maestre $(1988,56)$ manifiesta que la espectacularidad y suntuosidad de los decorados a la italiana era de tal magnitud, que Calderón mostraba su malestar, ya que a veces el arquitecto era más alabado que el autor del texto. Neumeister (1983, 719): "El escenógrafo es más importante que el poeta".

5 Zamora Vicente $(1984,154)$ afirma: "En ese teatro está todo, lo antiguo y lo moderno, lo nacional y lo extranjero. Lope supo fundir en una unidad admirable todos los elementos, formas o procedimientos que en las letras españolas corrían antes de él, ya maduros ya embrionarios".

6 Díez Borque $(1976,32)$ considera que el personaje del gracioso está bien delimitado dentro de la comedia y es el portavoz de todos los pasajes humorísticos que encontramos en ella. 
En cuanto a las coordenadas en las se desarrolla la acción Aubrun $(1976,148)$ considera que la comedia mitológica no se sitúa en ningún momento histórico preciso, ni en ningún lugar geográfico comprobado y presenta, preferentemente en las comedias de Calderón, cuatro niveles de interpretación: $1^{\circ}$ El sentido literal no está sometido a las leyes de verosimilitud; $2^{\circ} \mathrm{El}$ sentido moral no existe, pero sí existe un sentido ético; $3^{\circ} \mathrm{El}$ sentido alegórico (psicológico) es preponderante, ya que la comedia mitológica es una psicomaquia y $4^{\circ} \mathrm{El}$ sentido anagógico (espiritual) permanece entre las líneas del texto.

2.2. De las cuatrocientas setenta comedias que nos han llegado de Lope de Vega, sólo ocho ${ }^{7}$ están encuadradas como comedias mitológicas y todas, salvo Las mujeres sin hombre, se sirven de las Metamorfosis de Ovidio para su composición, o bien de la traducción que Jorge de Bustamante hizo de ésta. La primera que nos ha llegado es Adonis y Venus, llamada por el autor El premio de la hermosura y dedicada al duque de Pastrana. Fue compuesta en 1599 o $1604^{8}$ tomando el tema de Met. X 298-739, representada en el Parque de Lerma (1614) y publicada en 1621.

- El Perseo y la bella Andrómeda, compuesta entre 1610-1612 (o posterior a 1618) e inspirada en Met. IV 604-803 y Met.V 1-268, impresa en La parte decimosexta de las Comedias de Lope (1621).

- El vellocino de oro, se inspira en Met. VII 1 ss., es un espectáculo palaciego, representada en Aranjuez con motivo del cumpleaños de Felipe IV (1622) y publicada $\mathrm{n}$ año más tarde en La parte XIX de las Comedias de Lope.

- El amor enamorado, inspirado en Met. I 416-567 es la última de sus obras ya que Morley-Bruerton fechan su composición entre 1630 y 1632. Posiblemente se representó en el palacio del Buen Retiro (1635). Estas cuatro comedias en opinión de Mac Gaha son las únicas que Lope escribió para la representación cortesana.

- El laberinto de Creta lo compone entre 1610-1625, sirviéndose del relato ovidiano Met. VII 394-452 y Met. VIII 6-183.

- El marido más firme lo escribe entre 1621-1622. Recrea la historia de Orfeo y Eurídice relatada por Virgilio, Geórgicas IV 453 ss. y en Ovidio, Met. X 1-105 y 143-739 y Met. XI 1-66. Está dedicada a Manuel de Faria y Sousa. Fue publicada en La parte XX de sus comedias (1625). Esta comedia tiene algunos puntos de unión con La bella Aurora, inspirada en Met. VII 661-865, compuesta probablemente entre 1620-1625 y es una de comedias que fueron escritas y estrenadas después de haber sido ordenado sacerdote, es decir, en los últimos treinta años de su vida, al igual que los nueve Autos Sacramentales en los que reescribe alegóricamente algunos mitos, continuando así la moralización medieval de cuatro historias ovidianas (El laberinto del mundo, El divino Orfeo, El divino Jasón y Andrómeda y Perseo) que ya había tratado como comedias.

Martínez Berbel (2003) presenta un interesante estudio de siete de estas ocho comedias, con abundante información sobre cada una de ellas.

8 Menéndez Pelayo (1896, t. V, XL) estima que es anterior a 1604 al estar mencionada en la primera lista de $E l$ Peregrino. Confirman esta opinión Morley-Bruerton (1968, 52). 
En cuanto a Calderón la mitología en su obra es un pretexto para el lirismo o la velada alegoría. Se sirve de la idea capital del asunto mítico e intenta recrear lo esencial del mito. Todas estas obras mitológicas fueron escritas para las celebraciones reales de la corte. La primera fue La fiera, el rayo y la piedra (1652) que recoge el mito de Anaxárete (Met. XIV 699-771) y el de Pigmalión (Met. X 243-297). Siguieron Las fortunas de Andrómeda y Perseo (1653), Met. IV 604-803 y Met. V 1-268; El laurel de Apolo (1658), Met. I 452-567; La púrpura de la rosa (1660), Met. X 503-559 y 705-739; Celos aun del aire matan (1660); Céfalo y Pocris (1660), Met. VII 661-865, comedia burlesca; Eco y Narciso (1661), Met III 341-510; Apolo y Clímene (1661), Met. IV 190-270 y Fasti V 183 ss.; El hijo del Sol, Faetón (1661). Esta última, aunque toma el argumento de Met. II 1-400, tiene muy en cuenta el libro II, cap. XVIII de la obra de Pérez de Moya para presentar a Faetón como símbolo del orgullo.

A la vista de los títulos enumerados es evidente que ambos dramaturgos tratan de reescribir los mismos temas y la personalidad de estos poetas queda reflejada en cada una de sus obras, lo que llevó a Valbuena Prat $(1941,18$ s.) a decir: "Lope es un genio que vive, Calderón un genio que piensa". Los que más les interesan y en los que coinciden son los de carácter episódico cuyo tema principal es el amor, como es el caso de Adonis-Venus y el de Céfalo-Procris 9 . Por ello, precisamente voy a centrar mi atención en las dos comedias que tratan el mito de Adonis para ver cómo la dependencia de la fuente clásica es diferente en cada uno de ellos. Lope suele seguir más de cerca el mito en su totalidad, como voy a confirmar en su Adonis y Venus. En cambio, Calderón en La púrpura de la rosa crea una comedia que conserva la esencia del mito, pero no recoge la totalidad del mismo.

\section{Adonis y Venus de Lope de Vega}

El mito de Adonis no es de origen clásico, sino oriental, aunque nos ha llegado a través de la antigüedad grecolatina. Adonis, el dios muerto y llorado por las mujeres, era una divinidad siria o fenicia, al que ya hace referencia el profeta Ezequiel (VIII, $14)^{10}$. Tenía un carácter simbólico que no recogió Ovidio en su narración ${ }^{11}$, ni todos los dramaturgos españoles. Es uno de los mitos predilectos de la iconografía española del siglo XVII y más populares en las letras españolas por la gran cantidad de romances que lo tratan y por composiciones poéticas a cargo de poetas como Hurtado de Mendoza, Fábula de Adonis, Hipómenes y Atalanta; Juan de la Cueva ${ }^{12}$, Llanto de Venus a la muerte de Adonis; Lomas Cantoral, Amores y muerte de Adonis; Juan de Moncayo y Gurea, Fábula de Venus y Adonis; Pedro Soto de Rojas, Fábula de Adonis en su obra Fragmentos; Tirso de Molina, Fábula de Mirra, Venus y Adonis en Deleitar aprovechando; Shakespeare, Venus y Adonis y otros muchos que trataron este tema amoroso. En el teatro casi siempre ha sido tratado como ópera o tragedia

\footnotetext{
García Fuentes $(2011,389-400)$ analiza en este artículo la presencia de este mito de Ovidio en dos comedias de Calderón: Celos aun del aire matan y Céfalo y Procris.

10 Cf. Menéndez Pelayo $(1965,204)$.

11 Álvarez-Iglesias (1999, 578, n.1267) consideran que Ovidio es el primer poeta que se preocupa más de la historia de amor de Adonis y Afrodita que del culto como divinidad de la vegetación.

12 Cf. Cebrián García (1988).
} 
musical y es una de las más originales e interesantes, en la que se combina el argumento de Ovidio con personajes y situaciones de la tradición pastoril ${ }^{13}$.

3.1. Lope $^{14}$ dijo de su Adonis y Venus que está de suerte escrita que parece que el poeta se detuvo en ella. La escribió para ser representada en la corte de Felipe III. Lope intentó impresionar a su público aristocrático con la mejor obra que pudiera componer de ahí que McGaha $(1983,71$ s.) al referirse a ésta opinase así: "Adonis y Venus es radicalmente distinta de otras comedias que Lope había escrito hasta ese momento. Muy cuidadosamente estructurada, rica en lirismo y en la variedad de formas métricas que emplea, bastante más breve que la mayoría de las comedias lopescas e incorporando los efectos especiales más espectaculares que el dramaturgo había empleado hasta entonces, Adonis y Venus es un experimento atrevido y, en parte logrado, en la creación de un género dramático nuevo -por lo menos en España- que podríamos llamar - mascarada de corte-".

A estas palabras podemos añadir que utiliza el texto ovidiano como armazón e hipotexto de esa cuidadosa estructura para crear una pieza dramática que debe mucho a la tradición grecolatina, como voy a demostrar con el análisis y selección de los motivos míticos que dan a conocer la deuda con el relato ovidiano. Asimismo, señalo las innovaciones y la creatividad del dramaturgo al presentar a los personajes del relato mítico formando parte de la vida cotidiana de los pastores, creando una doble trama ${ }^{15}$.

Adonis y Venus es una obra palaciega y la única escrita antes de 1604 en la que se mezcla lo trágico y lo cómico; se desarrolla en tres actos con 2251 versos, en un ambiente de claro corte pastoril, como es habitual en este tipo de composición: selvas, prados, montes, fuentes, bosques y de abundantes resonancias bucólicas en la que los pastores Timbreo y Menandro se quejan del amor no correspondido de Camila y Albania y desean ir a consultar el oráculo de Febo. La ninfa Atalanta también se dirige al templo. Camila y Venus hablan sobre el amor, lo mismo hace la diosa con Cupido, quien hiere de amor a Venus y a Adonis. La leyenda de Atalanta e Hipómenes está relatada en su totalidad. Cupido se venga de su madre, porque le obligaba a ir a la escuela, al revelar a Apolo que Venus muere de amor por Adonis. La venganza de Apolo provoca finalmente la muerte de Adonis y el sufrimiento de Venus. El tema del amor y la belleza de los protagonistas son los dos componentes principales de esta obra y el motor que provoca la acción.

3.2. El acto primero centra su atención en tres motivos:

a) La consulta del oráculo de Apolo (dios oracular), por la ninfa Atalanta ${ }^{16}$ y otros pastores y pastoras que duplican la acción al desear saber qué les depara

13 Cristóbal López $(2002,127)$ afirma: "Uno de los más destacados fenómenos relativos al uso de la tradición clásica en estos dramas es la evidente contaminación que se da en estos dramas entre temática bucólica, de origen remotamente virgiliano (y más remotamente aún, teocriteo) y mitología".

14 Cf. Menéndez Pelayo (1949, vol. IV, 170): "Esta obra juntamente con El Perseo y El laberinto de Creta".

15 Valencia López $(2002,643)$ opina que, a la pareja de Adonis-Venus e Hipómenes-Atalanta, Lope añade otra doble intriga de tipo pastoril con dos parejas de amantes Camila-Timbreo y Albania-Menandro, creando en la comedia una trama cuádruple.

16 Ruiz de Elvira (1975, 329-335), siguiendo el schol. Theocr. III 40, afirma que hay dos Atalantas,, una de Arcadia, extraordinaria arquera, hija de Íaso, que destacaba por su fuerza y su destreza como cazadora y luchadora; la otra Atalanta de Beocia, gran corredora, hija de Esqueneo. que destacaba por preservar su virginidad y su calidad de invencible corredora. Ésta, al enamorarse del joven Hipómenes su competidor, pierde la carrera y, más tarde, la virginidad. 
el amor. Atalanta recibe de Apolo una respuesta clara, Ado. v. 362: "Tarde, Atalanta, y con peligro". Estas palabras parecen transcribir la traducción de Bustamante: "El matrimonio traerá peligro" que expresan de forma concisa las palabras pronunciadas por Apolo en Met. X 565 s.: "Nil opus est, Atalanta, tibi. Fuge coniugis usum./ Nec tamen effugies teque ipsa viva carebis".

b) La leyenda de Mirra (Ado. 540-597), madre de Adonis, está en un segundo plano al ser la pastora Camila la que se la cuenta a la diosa Venus, al suponer que la diosa no conocía al joven. Ensalza la belleza del joven y le confiesa su amor por Adonis. Este contenido responde, casi en su totalidad, a la reescritura de Met. X 298-524, pero al ser más breve (58 versos frente a los 204 de Ovidio) y no plasmar las dudas de la protagonista, eliminando por completo el sentimiento de culpa, es una prueba evidente de que sigue la traducción de Jorge de Bustamante y no el texto latino.

c) El enamoramiento de Venus producido por la actuación del rebelde Cupido que dispara una flecha voluntariamente a su madre para que vea el poder que tiene y para vengarse de ella, $A d o .631-634$ :

Hoy veréis si amor es Dios.

Ya tiro Venus repare:

Que aunque más mi madre sea,

La tengo de herir de amor.

La diosa declara abiertamente su amor con este juego de palabras, Ado. 705-707: "Bien dices que quiero a Marte, / no porque a Marte deseo, /sino porque quiero amarte".

En Ovidio la actuación de este niño es bastante diferente al presentarse en situación cariñosa con su madre a la que hiere involuntariamente por el roce de una de sus flechas, Met. X 525 s.: Namque pharetratus dum dat puer oscula matri;/ inscius extanti destrinxit harundine pectus. Esta herida provoca el que Venus se enamore de Adonis (Met. X 530: capta viri forma).

3.3. El acto segundo desarrolla, en su totalidad, todos los motivos que conforman la leyenda de Atalanta e Hipómenes. Es un relato secundario dentro del relato principal (metarrelato), con pequeñas variantes que matizan la versión ovidiana. Lope mantiene la filiación clásica presentando a Hipómenes, como hijo de Megareo, y a Atalanta, como hija de Esqueneo, pero la toponimia se modifica Arcadia, Chipre y Delfos por la tierra de los Sabeos en el suroeste de África. A diferencia de la versión ovidiana, en la que Venus cuenta a Adonis la historia de Atalanta ${ }^{17}$, aquí es Menandro el que informa a Hipómenes de la decisión que toma la ninfa Atalanta tras la consulta del oráculo:

a) Refugiarse en el bosque para mantener su castidad. Solamente se casaría con aquél, que la venciese en la carrera, $A d o .812-820$ :

Ella desde este día, por el monte

Que todo este horizonte muestra en torno,

Con varonil adorno entretenida

Más adelante (Ado. 1788-1830), Lope, para ser fiel al guión ovidiano y para prolongar la acción, recuerda que es Venus la que cuenta a Adonis la historia de Atalanta. 
Pasaba honesta vida descuidada.

Mas siendo deseada su hermosura

(que ésta no está segura aun entre fieras),

Pensó de mil maneras esconderse

$\mathrm{Y}$ vino a resolverse que al fin fuese

De aquel que la venciese

Hipómenes pregunta en qué había que vencerla y Menandro añade, Ado. 821827:

Escucha es tan ligera,

Que al viento en la carrera se adelanta.

Quiso, pues, Atalanta que corriesen

Los que la pretendiesen, y rendida, entregarse vencida al victorioso.

¡Oh caso lastimoso, que al vencido

que le cueste ha querido la cabeza.

Aquí subyace la totalidad del texto ovidiano de Met. X 567-570:
Territa sorte dei per opacas innuba silvas
vivit et instantem turbam violenta procorum
condicionem fugat « nec sum potienda, nisi » inquit
"victa prius cursu. Pedibus contendite mecum:
praemia veloci coniunx thalamique dabuntur,
mors premium tardis. Ea lex certaminis esto.

b) Hipómenes muestra su asombro y extrañeza ante esta actitud de la ninfa y de que algún joven quiera arriesgar su vida, en tres versos llenos de contenido filosófico, Ado. 832 ss.: "Por mortal hermosura, al fin prestada, / flor, sombra, viento, nada, ¿hay algún loco/ que se estime en tan poco?”. Evidente recreación de Met. X 576: Et "petitur cuiquam per tanta pericula coniunx?".

c) Hipómenes rectifica y se disculpa, con estas palabras, después de ver a la joven, Ado. 879 ss.:

¡Cuán en vano me espantaba

De aquel que por tu belleza

Una vida aventuraba.

Cifra de naturaleza

Donde su poder se acaba!

Que mil vidas que tuviera

todas por ti las perdiera.

Palabras que encierran el significado de Met. X 580 ss.: Obstipuit tollensque manus "ignoscite”, dixit/ "quos modo culpavi. Nondum mihi praemia nota, / quae peteretis, erant".

d) Atracción mutua de los dos jóvenes. Atalanta se enamora de Hipómenes, Ado. 922 s.: "De cuantos mancebos vi, / ninguno así me agradó". Estas palabras 
transcriben el sentido de Met. X, 609s.: molli vultu adspicit; y con mayor claridad el de Met. X 634s. en los que dice que si el destino no le negase el matrimonio, él sería el único con el que querría compartir su lecho (cum quo sociare cubilia uellem).

e) Atalanta le pide a Hipómenes que no participe en la carrera, que abandone la competición y desista de la empresa, por su corta edad y por la suerte que correrá si es vencido, Ado. 1002 ss.: "Vete, mancebo, y no quieras/ pagarme mal este amor:/ Mira que la muerte espera". Interpretando el contenido de Met. X 620 y 629: Dum licet, hospes, abi thalamosque relinque cruentos. [...] Utinan desistere uelles!

f) Atalanta pide a los dioses que le dejen vencer, al conocer que el joven está decidido a competir, Ado. 1016: ¡Cielos dejadle vencer!. Traduce el sentido de Met. X, 630: Aut, quoniam es demens, utinam velocior esses!

g) Hipómenes pide ayuda a Venus, ofreciéndole dos palomas, para salir airoso en su empresa amorosa, Ado. 1041-1052:
Venus, reina divina
De amor estrella pura,
Que el sol por su hermosura
Su rayo siempre inclina;
Soberano planeta,
Que amor al hombre influyes,
tú que de ingratos huyes,
mi ruego humilde aceta.
Dos palomas ${ }^{18}$ ofrezco
A tus aras sagradas,
De olivas coronadas
Si tanto bien merezco.

En Ovidio Hipómenes también solicita la ayuda de Citerea, para vencer en la carrera, pero no ofrece nada a cambio, Met. X 640 s.: Invocat Hippomenes "Cytherea" que "comprecor ausis/ adsit"ait "nostris et quos dedit, adiuvet ignes".

h) La diosa Venus, para favorecer al enamorado, le entrega tres manzanas de oro, y le indica cómo puede utilizarlas, para salir vencedor en la carrera, Ado. 1061-1066 y 1068-1077:

Hipómenes, yo vengo enternecida

De tus ruegos y lástimas, y quiero

Darte favor y remediar tu vida

Con una industria en que tu bien espero

Atalanta no puede ser vencida

Porque el viento veloz no es tan ligero.

$[\ldots \ldots \ldots . .$.

Pero con estas tres manzanas de oro,

Así la vencerás en la carrera.

18 Más tarde recuerda esto mismo, Ado. 1089: "Tuyas serán dos cándidas palomas". 
En viendo la ventaja, su decoro
Descompondrás echando la primera;
Si ves que la codicia del tesoro
La vence, la segunda y la tercera
Podrás echar; que mientras va por ellas,
Podrás dejar atrás sus plantas bellas.
Con esto, al palio llegarás primero,
Gozando el premio que mil vidas cuesta.

Esto resume el contenido de Met. X 649-651, donde se cuenta la entrega de las tres manzanas, traídas del campo de Támaso, en Chipre, y cómo debe utilizarlas:

Hinc tria forte mea veniens decerpta ferebam

Aurea poma manu nullique videnda nisi ipsi

Hippomenen adii docuique, quis usus in illis.

Lope amplía el contenido intercalando la conversación que Cupido mantiene con Jacinto, Narciso y Ganimedes, que interrumpen el relato de la leyenda de Atalanta, Ado. 1093-1148 y 1177-1206.

El hecho de que las lance por separado, para impresionar y distraer a la joven, es la reelaboración de un pasaje mucho más amplio recogido en Met. X 664-680.

i) Hipomenes alaba la belleza de Atalanta, después de la victoria. Lope se aleja del texto ovidiano porque, después de la victoria, no reconoce el apoyo de Venus al atribuirse a sí mismo el mérito de la misma y ensalzar la belleza de Atalanta por encima de la de Venus, Ado. 1410-1414:
Después
Que yo te vi más hermosa
Pongo esa diosa a tus pies.
No hay Venus ya, ni de amor
Otra diosa que Atalanta

j) Atalanta e Hipómenes son transformados en leones. La ingratitud del joven de no cumplir la promesa, y alabar éste la belleza de Atalanta por encima de la de Venus, obliga a Venus a transformarlos en leones en su templo, Ado. 1448-1450: “ ¡Vive Adonis, que he de daros/ la pena que merecéis, / y en leones transformaros!" En Ovidio, la diosa Venus, ofendida por no haberle agradecido la ayuda, lo castiga forzándolo a profanar el templo de la diosa Cibeles y es ésta la que los castiga, transformándolos en leones (Met X 698-704).

3.4. Acto tercero motivos más importantes:

a) El temor que Venus siente por Adonis, lo expresa con estas palabras, Ado.: 1708 s.: "Detente, por vida mía, / si la estimas, prenda amada". También este temor da pie a que la diosa cuente a su amado la historia de Atalanta, en 48 versos (Ado. 1787-1834), para que se libre de estos animales que pueden buscar venganza en él y le ruega que no vaya a cazar. Lope transcribe el contenido 
de Met. X 705-707, al insistir en que huya de las fieras que no dan la espalda a la huida, sino que ofrecen el pecho a la pelea, para que su valor no les perjudique a los dos. Este contenido lo plasma magníficamente el lienzo de Tiziano en el Museo del Prado (García Fuentes 2013, 168s.).

b) El valor del que alardea Adonis tranquiliza a Venus y Lope lo ha sabido recordar en su obra, ampliando en exceso el pasaje, al recordar que atravesó al fiero jabalí con su tridente y que mató un oso, al que le salió el alma por la boca (Ado. 1712-1742). Ovidio sólo evoca la rebeldía del joven, ya que el valor de Adonis se mantiene en contra de los consejos de Venus, Met. X 709: Sed stat monitis contraria uirtus.

c) Adonis duerme y sueña en el regazo de Venus ${ }^{19}$, Apolo los ve y le molesta que Venus esté con un mortal. Adonis le cuenta lo que ha soñado, Ado. 1923 s.: "Corta vida y triste muerte, / soñaba yo que tenía". Este motivo está ausente en Ovidio.

d) La muerte del amado en Ovidio la provoca la osadía y mala suerte del joven al herir y no matar a un jabalí que le clavó los colmillos en la ingle (Met. X 710716). En cambio, en Lope son los celos de Apolo que ayudado por el pastor Frondoso y la furia Tesifonte causan la muerte del joven, con estas palabras, Ado. 1891-1898:
Buscar quiero algún pastor
Que ayude a mi engaño, en tanto
Que Tesifonte se viste
De aquel animal airado
verán los cielos agora
que son celos, pues llegaron
a cegarme, si son celos
los celos averiguados.

e) El recuerdo que siempre quedará de este hecho, Ado. 2201 ss.: "Memoria de tu muerte y de mi luto/ Quedará de esta forma/ Tu cuerpo en flores mi dolor transforma".

Todas estas palabras son el eco ovidiano de Met. X 725-727: Luctus monimenta manebunt,/semper, Adoni, mei, repetitaque mortis imago/ annua plangoris peraget simulamina nostri ${ }^{20}$.

f) La transformación de la sangre de Adonis en flor. Lope, en un primer momento, interpreta que es el cuerpo de Adonis el que se transforma, según las palabras de Venus, Ado. 2203: "Tu cuerpo en flores mi dolor transforma", siguiendo la traducción de Bustamante ${ }^{21}$, pero enseguida rectifica la diosa, para

Cf. García Fuentes (2013, 167s.) Paolo Gagliari (el Veronés) plasmó un hermoso lienzo con este motivo.

Se hace referencia a la importante fiesta las Adonias, fiesta en honor de Adonis, para recordar la muerte del joven. Esta celebración tenía dos partes, una lúgubre en la que las mujeres vestidas de luto lloraban a la divinidad muerta y otra de alegría orgiástica, en la que alrededor del lecho de Adonis resucitado se reunían todos los emblemas del poder generador y vivificante, véase Menéndez Pelayo (1965, 204).

$21 \quad$ Sigue el texto de Bustamante $(1595,164$ s.): "Venus cuando volvió halló el cuerpo en la arena envuelto en gran abundancia de sangre. Viendo esto ella hizo gran duelo sobre él y decía: "En tanto el mundo durare yo haré por 
seguir a Ovidio, (Met. X 728: At cruor in florem mutabitur), diciendo que es su sangre la que se convierte en flor, Ado. 2208 ss.:

Ya que mi Adonis querido

Es muerto, y su roja sangre

Se ha vuelto en aquestas flores,

No es justo que de amor trate.

Yo me quiero recoger

entre las monjas Vestales.

No me busques más, Cupido.

Debo señalar que Ovidio, a diferencia de Lope, se detiene y amplía el texto cuando relata la transformación, en león, de Atalanta e Hipómenes y, en flor, de Adonis. Cuenta que Venus, dolida con el destino, dijo que la sangre de Adonis se convertiría en flor. A continuación, roció de oloroso néctar la sangre de Adonis y surgió de la sangre una flor del mismo color, como la del granado, pero su vida es efímera y la arrancan los mismos vientos que le dan nombre, la anémona (Met. X 731-739).

3.5. A pesar de la fidelidad al texto ovidiano ${ }^{22}$, existen innovaciones que me permiten hablar de la originalidad del dramaturgo y que servirán de inspiración a Calderón en La púrpura de la rosa:

a) Lope con mucha habilidad innova al generar un entramado dramático para recrear el relato ovidiano, desarrollar la acción en un ambiente bucólico y pastoril, prolongar la acción y alterar el orden con la marcha de Venus a Chipre, al situarla al final del acto primero Ado. 756 .

b) Las furias infernales son personajes que aparecen muchas veces en estas comedias, para llevar a cabo las venganzas. El dios Apolo pide ayuda a la furia Tesifonte para que vaya a los bosques de Arcadia y mate a Adonis, Ado. 1668-1675:

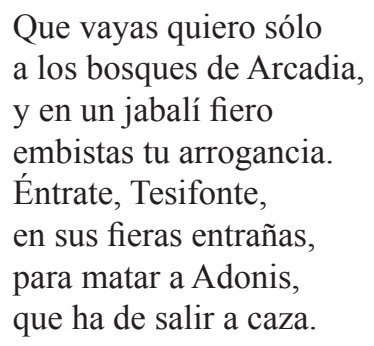

ti gran llanto". Esto dicho el cuerpo de Adonis fue luego mudado en una flor que suele llevar granos bermejos como granada".

22 Respecto a la dependencia ovidiana Ramos Jurado $(2001,29)$ afirma: "Lope no es el autor que se atiene servilmente al mito, a su trama y a su ambiente histórico, sino que lo adecua al presente, a su siglo, a su forma de entender la comedia. No es, pues, en sus comedias mitológicas un hermeneuta del mito ni un erudito en sentido estricto, sino un poeta, un creador, y como tal se vale del mito para sus propios fines". Desde nuestro punto de vista nos parece acertada la opinión, pero consideramos que hace una utilización muy particular del mito y que lo sigue muy de cerca, tratando de recoger todos los motivos que lo conforman, como podemos comprobar por el análisis realizado. 
c) Los dramaturgos dotan a Adonis de personalidad para mostrar sus sentimientos misóginos y expresar su temor y odio por las relaciones amorosas. Aquí se intenta justificar la actitud del joven al ser Adonis el resultado de una relación incestuosa que destrozó la vida de su madre.

d) Cupido (en Lope) y Amor (en Calderón) es uno de los personajes más complejos de la obra, participa activamente en el desarrollo de la acción. Critica la actitud amorosa de su madre y es el que incita a Apolo, en Lope, y a Marte, en Calderón, para que se produzca el fatal desenlace y acabe con la muerte de Adonis.

e) El triángulo amoroso con alguno de los protagonistas, Menandro, Camila y Adonis y Venus, Apolo y Adonis (en Lope) y Venus, Marte y Adonis (en Calderón).

f) La belleza de Venus es ensalzada por Adonis, Ado. 728-737.

g) El sueño premonitorio que tiene Adonis, cuando duerme sobre el regazo de Venus, Ado. 1923 s.: "Corta vida y triste muerte, / soñaba yo que tenía”. Nos recuerda el magnífico cuadro de Paolo Gagliari (El Veronés) en el Museo del Prado $^{23}$.

h) Lope desmitifica el relato al presentar a Cupido yendo a la escuela o jugando a los juegos típicos de la época, conversando con Jacinto, Narciso y Ganimedes, y a Venus pensando entrar de monja vestal, después de morir Adonis, Ado. 2212-2218.

i) La referencia al libre albedrío que hace a los personajes dueños y responsables de sus actos.

\section{La púrpura de la rosa de Calderón de la Barca}

Para tratar el mito de Adonis y Venus en un estilo alegórico similar al de sus Autos Sacramentales, Calderón escribió la comedia La púrpura de la rosa ${ }^{24}$, cuyo título tiene un valor simbólico, la púrpura resalta la gloria y las virtudes de los gobernantes y la rosa, entre sus muchos significados, indica el deseo amoroso.

El poeta reduce la historia a los amores de Venus y Adonis. Abre la comedia con Venus cazando en un bosque acompañada de sus ninfas y perseguida por un jabalí. Adonis corre en su ayuda y éste al saber que ella es Venus le cuenta la triste historia de su madre Mirra y que, al haber sido fruto de un amor prohibido, aborrece y renuncia al amor. Venus enamorada del joven pide a ayuda a su hijo Cupido y éste le dispara una flecha. Adonis, después de una jornada de caza, al ver a Venus, alaba su belleza y los dos se muestran enamorados. Entra en escena el dios Marte, amante de Venus, para crear el triángulo amoroso que propicie los celos, móvil del fatal

23 García Fuentes $(2013,167 \mathrm{~s}$.)

24 Cancelliere $(2001,123)$ aporta datos interesantes para esta obra que el mismo Calderón llamó zarzuela y otros la consideran ópera: "En 1659 en el Coliseo se realiza el decorado de La púrpura de la rosa que legitima en el género de la representación-música la costumbre del espectáculo enteramente cantado y con música. Los decorados son de Antonio María Antonozzi, escenógrafo en la Corte después del Fontana, del Lotti y del Baccio del Bianco. La sucesión de los cinco decorados distintos - de bosque, de gruta, de jardines, de monte y de cielo- reuniendo todos los cambios en el arco diegético de un único acto, representa una maravillosa aplicación de la scaena ductilis con función espectacular que en Italia había dado sus primeras pruebas con los Intermezzi de Buontalenti (1598) y que se había codificado como diéresis para escenas en los grandes decorados europeos realizados por Torelli ...". 
desenlace; Belona, hermana de Marte, Dragón, soldados y dos campesinos, Chato y Celfa, que bromean sobre el matrimonio. Aparece una gruta donde entra Marte y allí ve al Temor, la Sospecha, la Envidia, la Ira y al Desengaño que repite: "Ay de aquel que en principio de celos, / huyendo el amor no le deja que huya". Con un espejo el Desengaño permite a Marte ver a los enamorados y le aconseja olvidarse de ese amor. Adonis es herido mortalmente por un jabalí, Venus lamenta su muerte y Júpiter conmovido por la desgracia de los enamorados los eleva al Cielo, Adonis en forma de flor y a Venus como la estrella de la tarde.

Esta historia de amor y de celos, modelada en un entramado mítico conocido, pero desarrollada con nuevos elementos y personajes que le dan personalidad propia, ofrece una reescritura novedosa e independiente del mito que se debe al tipo de composición y a la creatividad del poeta.

Fue escrita en un solo acto con un total de 1520 versos, para ser totalmente can$\operatorname{tada}^{25}$, con música de Juan Hidalgo. Después de publicarse la Paz de los Pirineos que ponía fin a la guerra de los Treinta Años, esta obra fue representada con motivo de las bodas reales de la infanta de España $\mathrm{M}^{\mathrm{a}}$ Teresa con Luis XIV de Francia, en el palacio del Buen Retiro, el diecisiete de enero de 1660 e impresa en la Tercera parte de las comedias de Calderón (1664). Fue la primera ópera que se representó en Lima (Perú) en 1701. Valbuena Briones $(1969,1765)$ considera que la cuidadosa estructura dramática, la belleza lírica y el valor plástico y alegórico de esta ópera la proclaman obra de singular mérito y calidad.

4.1. Esta obra debe el tema a Ovidio y la trama de la acción a Lope. Los ecos ovidianos podemos concretarlos en:

a) La belleza del joven Adonis que impacta y cautiva a la diosa, después de haberle salvado la vida, al librarla de la violencia de un jabalí (Met X 524 y 529 y Purp. 55-58).

b) La breve historia de Mirra, que Calderón, a diferencia de Ovidio, pone en boca de Adonis, para justificar su desdén hacia las mujeres y hacia el dios Amor que priva de la razón (Met. X 560-704 y Purp. 103-147²6).

c) La flecha o arpón que el dios Amor dispara a Adonis cuando está dormido (Purp. 505-513), a instancias de su madre, Venus, al no verse correspondida en su amor y al conocer que el joven despreciaba el poder del dios niño (Purp. 490-497). En Ovidio es Cupido el que, involuntariamente, le hizo una herida con una de sus flechas que dio origen a la pasión amorosa de Venus hacia Adonis (Met. X 525 ss.).

d) El gemido del moribundo Adonis que Venus reconoce. Calderón transcribe el contenido de Met. X 719: (Cytherea) agnovit longe gemitum morientis en las palabras que Venus dice en Purp. 1375 ss.: "Que es cuyo temo el gemido, / y cuyo imagino el golpe, / Suyo es, sin duda (ay de mi !)”.

25 Cotarelo y Mori $(2000,15)$ considera a Calderón el fundador de la Zarzuela por las palabras que éste pone en boca de uno de los personajes, en la loa de La púrpura de la rosa: "Por señas que habrá de ser/ toda música, que intenta/ introducir este estilo, / porque otras naciones vean / competidos sus primores".

26 En estos versos Adonis declara que es un hijo aborrecido, desgraciado, hurto de amante traición, bastardo embrión, maldecido por sus padres, que su madre se convirtió en un árbol y que por eso él huye de las mujeres y del amor. 
e) La muerte y transformación que sufre Adonis. Calderón posiblemente, siguiendo a Lope, en un primer momento cuenta que es la ninfa Cintia, la que compadeciéndose de Venus y olvidando sus rencores le dice lo que ha visto al amanecer, Purp. 1389 ss.:

No sé que vivo cadáver

Desde la cumbre del monte

Rosas deshojadas vierte

A un valle que las recoge.

A continuación, Belona, hermana de Marte, le dice que teme que la verdad le informe y que sienta saber que es Adonis el que con su sangre infunde nuevo espíritu a las flores, Purp. 1404-1409. El dios Amor es el que expresa con claridad que es la sangre la que se convierte en flor, Purp. 1471 y 14751486.:

Júpiter, pues, conmovido
[ ... ]
De esa derramada sangre
Quiere que una flor se forme,
Y que de aquella se vistan
Roja púrpura las flores.
Para que en tierra y en cielo
Estrella y flor se coloquen;
A cuya causa, subiendo.
Donde entrambos se coronen
Verás que desde este día,
Con la nueva luz de Adonis,
Sale la estrella de Venus
Al tiempo que el Sol se pone.

f) Venus desea que su recuerdo viva eternamente y así se lo dice a Marte, Purp. 1466 ss.: "Tanto, que porque tus celos/ Su mayor triunfo no borren, / Vivirá a su ruego eterno". Transcripción de Met. X 725.

\subsection{Calderón debe a Lope:}

a) El sueño premonitorio de Adonis que se queda dormido a la sombra de unos troncos y Venus lo encuentra soñando y diciendo, Purp. 432 s.; 461 y 4 y 463 .: ¡Ay de mí! / Que me da muerte a quien la vida di! A continuación cuenta a Venus el sueño, en el que se le anuncia que va a morir por el ataque de un jabalí y la transformación que sufriría su sangre, Purp. 534-543:

Soñé

Que el fiero jabalí

Que a ti te daba muerte,

Volviendo contra mi

Las aceradas corvas 

Navajas de marfil
Con mi sangre manchaba
Las rosas, que hasta aquí
De nieve fueron, para
Que fuesen de carmín.

b) La belleza de la diosa Venus ensalzada por Adonis, Calderón, Purp. 587-611.

c) El triángulo amoroso de Marte, Venus y Adonis y Celfa, Chato y Dragón que provoca los celos.

d) La misoginia del huraño y despreciativo Adonis que muestra hacia las mujeres.

e) La intervención de una furia infernal. Marte, sintiendo celos de Adonis y para vengarse de la injuria del joven, pide a la furia Megera que vengue su injuria y revista en el jabalí toda su saña, Purp. 1296 ss.:
¡Oh tú, Megera,
Que de las tres Furias eres
La que más a Marte asiste,
En aquel bruto reviste
Toda la saña que adquieres ! side:

4.3. La originalidad e innovación de Calderón, respecto a Ovidio y a Lope, re-

a) En crear un escenario complicado con muchos efectos especiales y abundantes personajes, no insertos en el mito ovidiano, y en la inclusión de Marte, como amante celoso ${ }^{27}$.

b) En la jerarquización y tratamiento de sus personajes, en su actitud moralista y en la inserción de la gruta donde aparecen los personajes alegóricos: el Temor, la Sospecha, la Envidia, la Ira y el Desengaño, para ampliar el tema de los celos que Venus provoca en Marte.

c) En la flecha o arpón que el dios Amor dispara a Adonis a instancias de su madre, al conocer que Venus está agradecida, porque el joven le ha salvado la vida y airada, porque no ha conseguido enamorarlo. Por todo esto, Amor le oprime con su yugo, cuando el joven está dormido, Purp. 506-517.

Este hecho lo recuerda Venus al final de la obra, Purp. 1455 s.: "Flechas le tiró el Amor, / temida deidad del joven".

d) En la ausencia del viaje de Venus antes de producirse la muerte del joven Adonis.

e) En ofrecer una versión más oscura y simbólica, tras la muerte de Adonis y subir al cielo Venus y Adonis, mientras el sol se oculta y sale una estrella, significando el triunfo del amor, frente a los celos de Marte que significan la crueldad de la guerra.

En efecto, la diferencia entre estos autores la resume con estas palabras Alborg (1970, 660 s.): "Hay alguna diferente entre la comedia de Lope y la de

\footnotetext{
27 Los celos era un tema recurrente en el teatro del Siglo de Oro y Calderón lo trata con cierta amplitud para que la infanta y su prometido no lo padezcan. $C f$. Morales-González (2007).
} 
Calderón ya que este último sustituye la espontánea frescura, la desenvuelta naturalidad del lenguaje de Lope por una estudiada acumulación de artificios estilísticos donde tienen cabida todas las innovaciones del cultismo y del conceptismo que se armonizan amigablemente en su obra". En efecto, frente a la naturalidad de Lope, Calderón ofrece un estilo artificioso.

\section{Conclusiones}

Después de haber analizado estas dos obras y haber seleccionado los motivos que conforman el mito, únicamente, podemos concluir afirmando que Ovidio es la fuente de los mitos que estos dramaturgos revitalizan. Ambos dramaturgos sienten preferencia por los mismos temas y tratan de reescribirlos con su impronta personal, impregnándolos de su propio sentimiento, su carácter y su estilo.

Lope sigue casi al pie de la letra el texto latino o la traducción de Bustamante y, basándose en la trama mítica, genera un entramado dramático y crea una obra desmitificada, sin ningún valor simbólico ni exegético, pero con personalidad propia y con fines determinados. El poeta demuestra su gran conocimiento del mundo clásico al intercalar en el drama muchas alusiones a personajes mitológicos.

Calderón, por el contrario, no recoge la totalidad del mito ovidiano, sino lo esencial, la idea capital, sigue las líneas trazadas por Lope de las que se sirve y como habilísimo arquitecto teatral sabe buscar el sentido subyacente del mito y ofrecer una interpretación filosófica y ejemplarizante, lo que le aleja de la realidad.

La originalidad del poeta reside en la jerarquización y tratamiento de los personajes, en su actitud moralista, en la inclusión de Marte, como amante celoso, la gruta de los celos y personajes alegóricos como el Desengaño, el Miedo, la Sospecha, la Envidia, la Cólera y la Amargura.

Lo más meritorio de estos verdaderos creadores Lope y Calderón reside, no sólo en las innovaciones que han aportado, respecto al texto de Ovidio, como hemos ido señalando en sus obras, sino también en haber sabido transformar la esencia del mito en una obra moderna, original y capaz de entusiasmar al público del siglo XVII, acercando la mitología de forma atractiva y desmitificada a la sociedad de su época.

Por todo lo dicho, es obvio que Lope fue el iniciador de estas composiciones en España y Calderón es el que reafirmó la comedia mitológica, al haber sabido combinar espectáculo, poesía y música, tomando como modelo la ópera italiana.

\section{Referencias Bibliográficas}

\subsection{Fuentes}

Bustamante, J. (1595), Las transformaciones de Ovidio en lengua española, Amberes, BH de la UCM.

Calderón de la Barca, La púrpura de la rosa, Tercera parte de sus comedias, Francisco Sanz, BN, R/11347.

Ovidio Nasón, P. (1990), Metamorfosis, Texto revisado y traducido por A. Ruiz de Elvira, Alma Mater, Madrid. 
Vega Carpio, F. Lope de, (1965), Obras de Lope de Vega, Comedias pastoriles y comedias mitológicas, t. XII I, BAE, (ed.) Menéndez Pelayo, 339-373. Madrid.

Vega Carpio, F. Lope de, (2016), Adonis y Venus: Tragedia/ Lope de Vega. Biblioteca Virtual Miguel de Cervantes. Oleza, Joan. Alicante.

\subsection{Estudios}

Alborg, J. L. (1970), Historia de la Literatura Española, época barroca, Gredos, Madrid, tomo II, $660 \mathrm{~s}$.

Arellano, I. (1995), Historia del teatro español del siglo XVII, Madrid, Cátedra.

Álvarez, C.-Iglesias, R. (1999), Ovidio. Metamorfosis, Madrid, Cátedra.

Arróniz, O. (1969), La influencia italiana en el nacimiento de la comedia española, Madrid, Gredos.

Aubrun, Ch., (1976), "Estructura y significación de las comedias mitológicas de Cálderon”, Hacia Calderón (148-155), Tercer coloquio Anglogermano, H. Flascher (ed.), BerlinNew York.

Becker, D. (1989), "El teatro palaciego y la música en la segunda mitad del siglo XVII”, Actas del IX Congreso de la Asociación de Hispanistas (1986 Berlín), Frankfurt am Main, 1989, 353-364.

Cancelliere, E. (2001), “Calderón y el teatro de corte”, Cervantes, nº 0 marzo 2001, 117-132.

Cebrián García, J. (1988), El mito de Adonis en la poesía de la Edad de Oro. Barcelona.

Chapman, W.G. (1954), "Las comedias mitológicas de Calderón", Revista de Literatura (1954), n ${ }^{\circ} 5,35-67$.

Cotarelo y Mori, E. (2000), Historia de la Zarzuela, Madrid.

Cristóbal López, V. (2002), "Notas de tradición clásica en los dramas mitológicos de Calderón”, en Calderón en Europa, J. Huerta Calvo (et alii eds.), Madrid, 125-135.

Díez Borque, J. Ma (1976), La sociología de la comedia española del siglo XVII, Madrid, Castalia

Egido, A. (2000), “La majestad de la rosa”, en Calderón. Protagonista eminente del Barroco europeo, Kassel, Reichenbergen, 193-201.

García Fuentes, $M^{\mathrm{a}}$ C. (2011), "El mito de Céfalo y Procris en las comedias de Calderón de la Barca", Perfiles de Grecia y Roma, III, Villa, González e Hinojo (eds.), 389-407. Madrid.

García Fuentes, M ${ }^{\mathrm{a}}$ C. (2013), Mitos de las Metamorfosis de Ovidio en la Iconografía del Museo del Prado, Madrid.

Haverbeck, E. (1975), “El tema mitológico en el teatro de Calderón”, Anejos de Estudios Filológicos, 6, Chile.

Haverbeck, E. (2005), “El teatro de Calderón Mitología y cosmovisión barroca”, La mitología clásica en la literatura española. J. A. López Férez (ed.), Madrid 507- 551.

Maestre, R. (1988) "La gran maquinaria en las comedias mitológicas de Calderón de la Barca", en El mito en el teatro clásico español, Ruiz Ramón y Oliva (eds.), Taurus Madrid, 58-81.

Martínez Berbel, J. A. (2003), El mundo mitológico de Lope de Vega, Madrid.

McGaha, M. D. (1983), "Las comedias mitológicas de Lope de Vega", Estudios sobre el Siglo de Oro en homenaje a Raymond R. MacCurdy, Cátedra, Madrid, 67-82.

Mckendrick, (1994), El teatro en España (1490-1700), Palma de Mallorca.

Menéndez Pelayo, M. (1896), Comedias mitológicas. Comedias de asunto extranjero, Observaciones preliminares en obras de Lope de Vega, t. V, XL. Madrid.

Menéndez y Pelayo, M. (1949), Estudios sobre el teatro de Lope de Vega, Santander: Aldus, S. A. vol. IV. 
Morales Raya, R. - González Dengra, M. (2007), La pasión de los celos en el teatro del siglo de Oro, Actas del III Curso sobre teoría y práctica del teatro, Granada.

Morley S. Gr.- Bruerton, C. (1968), Cronología de las comedias de Lope de Vega, Madrid, Gredos.

Neumeister, S. (2000), Mito clásico y ostentación. Los dramas mitológicos de Calderón. Kassel. (ed.) Reichenberger, Zaragoza.

Neumeister, S. (1983), “Calderón y el mito clásico (Andrómeda y Perseo). Auto Sacramental y fiesta de Corte”, Actas Cong. Inter. Sobre Calderón, Madrid, 713-721.

Pérez de Moya, J. (1995), Philosofía secreta. Edición de C. Clavería, Cátedra, Madrid.

Ramos Jurado, E. (2001), “Comedia mitológica y comedia histórica. La tradición clásica en Lope de Vega", Cuatro estudios sobre tradición clásica en la Literatura Española, Cádiz, 14-43.

Valbuena Briones, A. (1969), Obras completas de Calderón de la Barca, t. II, Aguilar, Madrid.

Valbuena Prat, A. (1941), Calderón, su personalidad, su arte dramático, su estilo y su obra, Barcelona.

Valbuena Prat, A. (1974), El teatro español en su Siglo de Oro, Planeta, Barcelona

Valencia López, N. (2002), Estudio de las comedias mitológicas de Lope de Vega, Madrid.

Zamora Vicente, A. (1984), Lope de Vega, Barcelona, Salvat. 